\title{
Estimation of residual life of a cutting tool used in a machining process
}

\author{
Sourath Ghosh ${ }^{1}$, Sukanta Kumar Naskar² and Nirmal Kumar Mandal ${ }^{3}$ \\ ${ }^{1}$ Manufacturing Technology Department, National Institute of Technical Teachers' Training \& Research, Kolkata, India \\ ${ }^{2}$ Education and Management Department, National Institute of Technical Teachers' Training \& Research, Kolkata, India \\ ${ }^{3}$ Mechanical Engineering Department, National Institute of Technical Teachers' Training \& Research, Kolkata, India
}

\begin{abstract}
A significant part of cost of machining is associated with non-optimum use of cutting tool. Moreover cutting tool failure is responsible for almost $20 \%$ of the machining downtime. Thus, having knowledge of residual life of cutting tool is highly recommended so as to maximise the availability time and reduce the machining cost. The aim of this work is to find out residual life of a worn cutting tool which has been used for turning of Ti-6Al-4V alloy under constant cutting condition. The lognormal distribution is used to model the cutting tool life data. Remaining useful life of cutting tool is estimated using Mean Remaining Life (MRL) function. The results obtained from model are compared with the experimental results and it shows good agreement.
\end{abstract}

\section{Introduction}

Aim of modern manufacturing industry is to produce economical and reliable product along with good quality. Quality of machining product is generally referred as surface finish and accuracy in dimensions, which are highly dependent on the condition of cutting tool. Besides product quality, tool failure puts high impact on machining system and productivity. Moreover, in the total cost of machining, tooling cost accounts for a significant part (approximately 25\%) [1]. Most of the time cutting tools are either overused or underused with respect to optimum tool life. Study suggests that, cutting tools are typically utilised only up to $70-80 \%$ of its optimum life [2]. Hence, the prediction of remaining useful life (RUL) of cutting tool is important when a significant amount of cost is involved in a machining process.

Till now many researchers have developed various models for estimating cutting tool life. Devor, et al [3] concluded that the life span of cutting tool is a probabilistic phenomenon. Based on this fact, till now different reliability model has been proposed [4-5]. Rodriguez, et al [6] suggested a strategy of optimum tool replenishment based on analysis of cutting tool reliability. Xiao-Sheng, et al [7] presented brief review on recent developments of various models for estimating the RUL. Benkedjouh, et al [8] proposed a methodology for estimating the remaining useful life of cutting inserts which is based on the support vector regression. Gebraeel, et al [9] used artificial neural network approach for predicting remaining life of bearing. Aramesh, et al [10] introduced a model for predicting the remaining tool life in variable machining conditions using proportion hazard model. In this paper, the weibull distribution was used for modelling baseline hazard function of PHM.

The aim of this study is to present a probabilistic approach to assess useful remaining life of a worn cutting tool which has been used for turning of Ti-6Al-4V alloy under constant cutting condition. The lognormal distribution is used to fit the tool life data. Finally, Mean Remaining Life (MRL) equation is used to estimate expected residual life of cutting tool.

\section{Tool Wear}

Failure of cutting tool mainly occurs due to gradual blunting of cutting edge. Tool wear which takes place on the rake surface of the tool is called crater wear and which occurs on the flank surface called flank wear. Flank wear being the most predominant wear mechanism, maximum length of flank wear $\left(V B_{\max }\right)$ is generally used as failure criteria for determining tool life. However, depending on the desired application crater wear could also be used as failure criteria [11].

\footnotetext{
${ }^{1}$ Sourath Ghosh: sourath93@gmail.com
} 
As shown in Fig. 1, a typical tool flank wear curve involves three different states. At the initial state, the rate of tool wear is high which is known as rapid initial wear state. Next, at the steady state, wear rate remains almost constant followed by the accelerating wear state where tools wear out very rapidly.

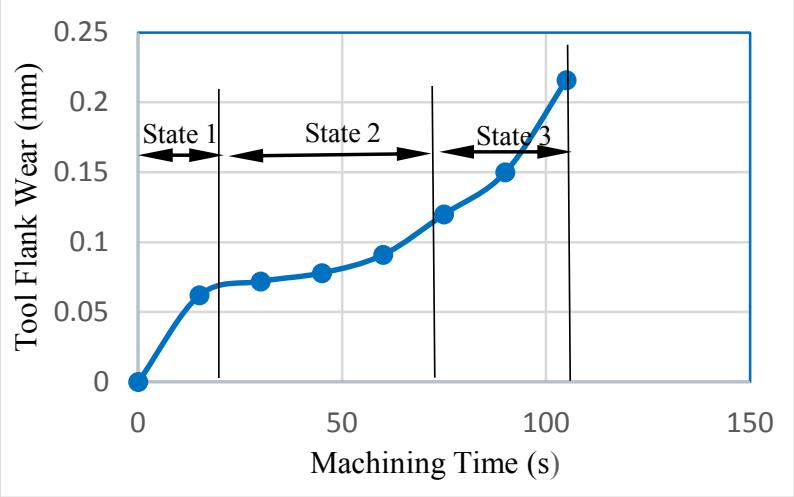

Fig. 1. Different states of flank wear

\section{Experiment Setup}

Dry turning operations were performed on MAXTURN Plus CNC turning centre. Fig. 2 shows the experimental setup used in this study. Cylindrical bar made up of Ti$6 \mathrm{Al}-4 \mathrm{~V}$ alloy was used as work piece material. Turning tool chosen for this study was TiN coated tungsten carbide insert having specification CNMG 120408 as shown in Fig. 3.

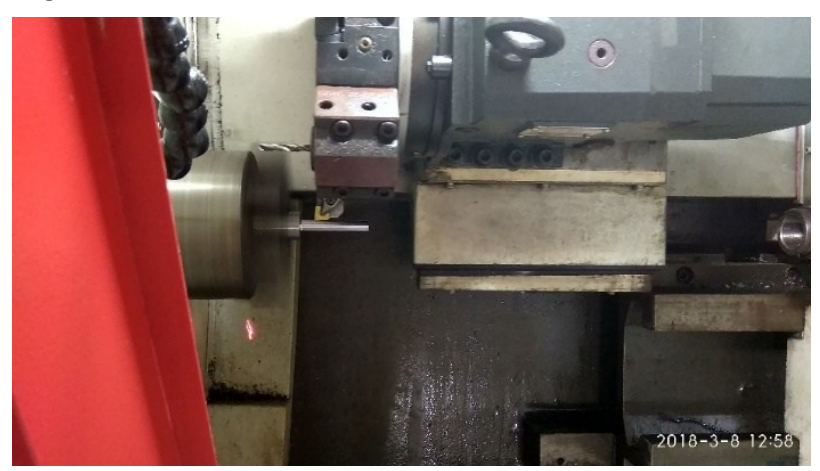

Fig. 2. The experimental setup

Experiments were performed using total eight number of new tool inserts. Turning operations were carried out for each tool under constant cutting parameters. Cutting parameters are chosen based on the supplier's recommendations which are listed in Table 1.

Table 1. Machining parameters

\begin{tabular}{cccc}
\hline Parameters & $\begin{array}{c}\text { Speed } \\
(\mathrm{m} / \mathrm{min})\end{array}$ & $\begin{array}{c}\text { Feed Rate } \\
(\mathrm{mm} / \mathbf{r e v})\end{array}$ & $\begin{array}{c}\text { Depth of } \\
\text { Cut } \\
(\mathrm{mm})\end{array}$ \\
\hline
\end{tabular}

Value

50

0.15

0.2

While each test, sequential observations of flank wear were performed using Upright Materials Microscope Leica DM2700 M as shown in Fig.5. For example, the experimental data of sequential wear measurements for tool-3 is shown in Table 2. The same procedure is repeated for each new tools.

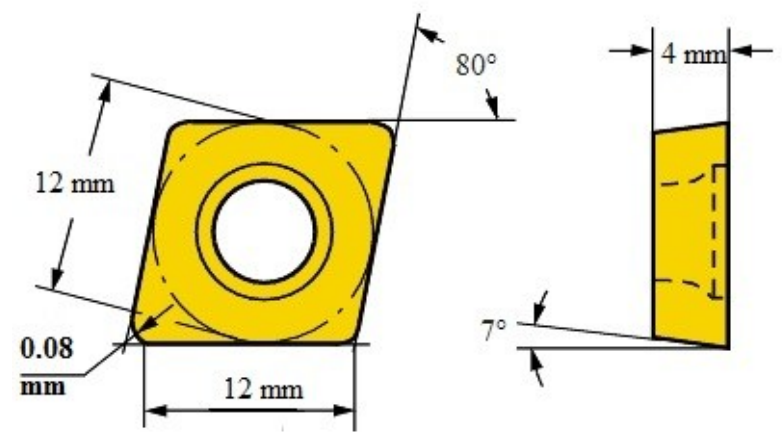

Fig. 3. Geometry of insert type tool (CNMG 120408) [16]

Table 2. Progressive wear of tool-3

\begin{tabular}{ccc}
\hline $\begin{array}{c}\text { Sequential } \\
\text { measurement } \\
\text { no. }\end{array}$ & $\begin{array}{c}\text { Machining } \\
\text { Time (s) }\end{array}$ & $\begin{array}{c}\text { Tool Wear } \\
(\mathbf{m m})\end{array}$ \\
\hline 1 & 0 & 0 \\
\hline 2 & 150 & 0.064 \\
\hline 3 & 300 & 0.079 \\
\hline 4 & 450 & 0.103 \\
\hline 5 & 600 & 0.121 \\
\hline 6 & 750 & 0.133 \\
\hline 7 & 900 & 0.146 \\
\hline 8 & 1050 & 0.153 \\
\hline
\end{tabular}

It is assumed that nature of the progression of tool wear is linear [12] between two measurement points as shown in Fig. 4. Time-to-failure (t) corresponding to the threshold limit $\left(V B_{\max }=0.15 \mathrm{~mm}\right)$ is calculated by interpolating between last two observations $\left(i_{t h}\right.$ and $\left.(i+1)_{t h}\right)$ by using equation (1). This procedure is performed for the each tools and the obtained results are presented in Table 3.

$$
\frac{t-t_{i}}{t_{i+1}-t_{i}}=\frac{V B_{\max }-V B_{i}}{V B_{i+1}-V B_{i}}
$$

Table 3. Tool life data for eight inserts

\begin{tabular}{cc}
\hline Tool Id & Tool Life (s) \\
\hline 1 & 912 \\
\hline 2 & 873 \\
\hline 3 & 982 \\
\hline 4 & 1018 \\
\hline 5 & 958 \\
\hline 6 & 1007 \\
\hline 7 & 854 \\
\hline 8 & 898 \\
\hline
\end{tabular}

\section{Methodology}

Eight number of cutting tool inserts are used for this study. While machining, sequential observations (measurements of tool flank wear) are performed until critical tool wear level is reached. Same procedure is carried out for eight inserts. 
Time to failure data is calculated for each insert by the regression process between last two observation points.

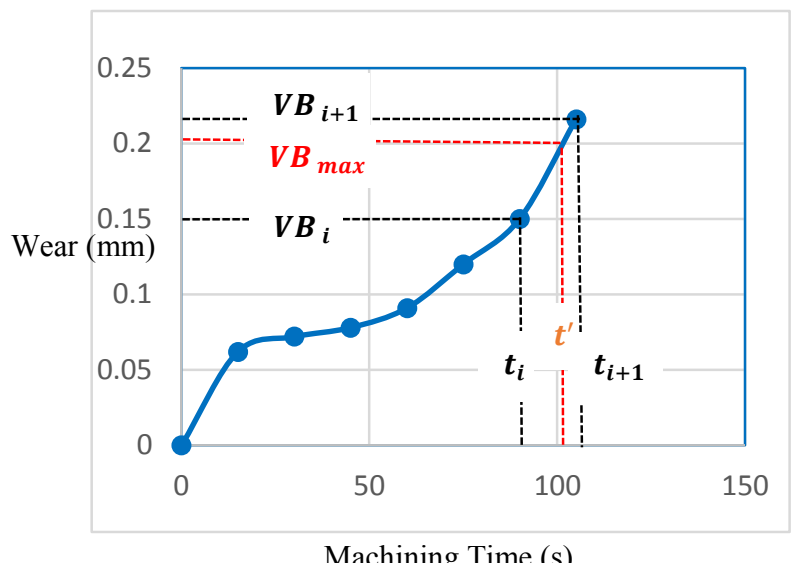

Fig. 4. Linear variation of tool flank wear between two points

Tool wear threshold limit is chosen based upon the economic aspect of machining. As, once the tool gets worn out significantly, it effects the surface finish and dimensional accuracy of machining product. In this study, maximum tool flank wear, $V B_{\max }=0.15 \mathrm{~mm}$, is taken as failure criteria. Which means, machining time corresponding to tool flank wear of $0.15 \mathrm{~mm}$ is considered as useful tool life.

In this study, lognormal distribution is used to fit time-to-failure data of eight inserts. From previous literature, it can be stated that lognormal distribution describes tool life accurately over other distributions [13]. The probability density function $f(t)$, for lognormal distribution is represented as follow:

$$
f(t)=\frac{1}{\sigma t \sqrt{2 \pi}} e^{\left[-\frac{(\ln t-\mu)^{2}}{2 \sigma^{2}}\right]}
$$

Where, $\sigma$ and $\mu$ denote the standard deviations and mean respectively and $\mathrm{t}$ represents tool life as continuous variable. The corresponding cumulative distribution function $\mathrm{F}(\mathrm{t})$, for lognormal distribution can be derived using the following relationship:

$$
\begin{aligned}
F(t) & =\int_{0}^{t} f(t) d t \\
& =\int_{0}^{t} \frac{1}{\sigma t \sqrt{2 \pi}} e^{\left[-\frac{(\ln t-\mu)^{2}}{2 \sigma^{2}}\right]} d t
\end{aligned}
$$

Consequently, the reliability function $R(t)$, for lognormal distribution can be obtained from following relation:

$$
\begin{aligned}
R(t) & =1-F(t) \\
& =1-\int_{0}^{t} \frac{1}{\sigma t \sqrt{2 \pi}} e^{\left[-\frac{(\ln t-\mu)^{2}}{2 \sigma^{2}}\right]} d t
\end{aligned}
$$

After constructing probability density function and reliability function, next step is to estimate the useful residual life of cutting tool using mean residual life function (MRL) [14]. Given that a tool has used for machining up to a certain time $t_{o}$, the expected residual life of the tool from that observation point can be calculated by the following equation:

$$
\operatorname{MRL}\left(t_{o}\right)=\frac{\int_{t_{o}}^{\alpha} t \cdot f(t) d t}{R\left(t_{o}\right)}-t_{o}
$$

\section{Results and discussion}

Firstly, turning operation is performed for each tool and tool life data are collected as shown in Table 3. Maximum likelihood estimation (MLE) method is used to calculate unknown parameters ( $\mu$ and $\sigma$ ) of Lognormal distribution using experimental data set [15]. This MLE is performed using the statistical software R. The estimated parameters of lognormal distribution are shown in Table4 and corresponding probability density function is shown in
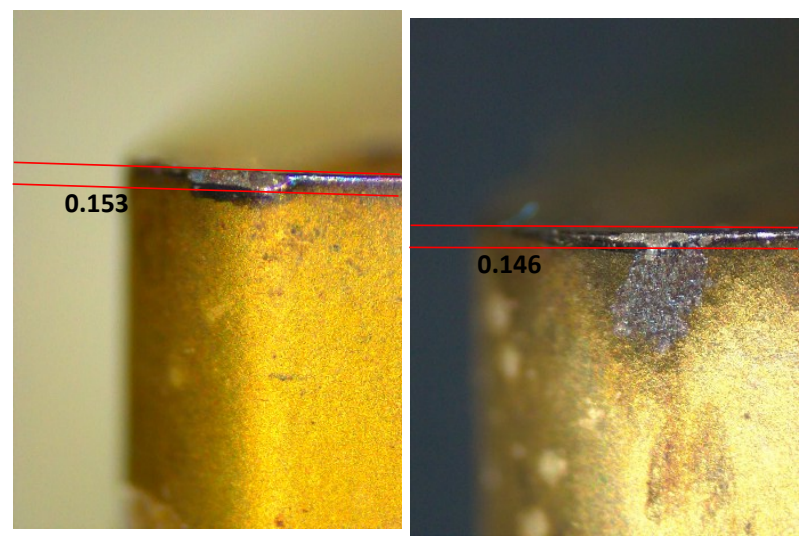

Fig. 5. Worn-out cutting edge after machining

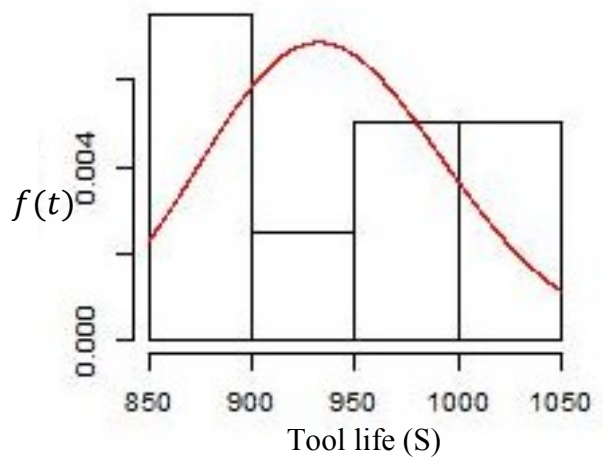

Fig. 6. Probability density function

After estimating distribution parameters and constructing reliability model, the next step is to calculate expected residual life. This calculation is done by the help of Matlab software.

Table 4. Parameters of Lognormal distribution

\begin{tabular}{ccc}
\hline Parameters & $\boldsymbol{\mu}$ & $\boldsymbol{\sigma}$ \\
\hline Estimated value & 6.842 & 0.062 \\
\hline
\end{tabular}

Let a cutting tool insert which already used $t_{r}=120$ (s) while operating under the same constant cutting parameters, then it's Mean Residual Life will be given by the Eq. 6 as below: 


$$
\operatorname{MRL}(120)=\frac{\int_{120}^{\infty} t . f(t) d t}{R(120)}-120
$$

Three Confirmation tests were conducted on three cutting tools and the estimated results of residual life from the statistical model are presented in Table 5. In order to check the accuracy of the estimated result, the residual life was observed by further machining with the tools and noted down as presented in Table 5.

Table 5. Comparison between estimated and experimental result

\begin{tabular}{ccccc}
\hline $\begin{array}{c}\text { S1. } \\
\text { no }\end{array}$ & $\begin{array}{c}\text { Consumed } \\
\text { life } \\
(\mathrm{s})\end{array}$ & $\begin{array}{c}\text { Residual } \\
\text { life from } \\
\text { model (s) }\end{array}$ & $\begin{array}{c}\text { Residual } \\
\text { life from } \\
\text { experiment } \\
(\mathrm{s})\end{array}$ & $\begin{array}{c}\text { Perce } \\
\text { nt-age } \\
\text { error } \\
(\%)\end{array}$ \\
\hline $\mathbf{1}$ & 120 & 818.961 & 837.000 & 2.15 \\
\hline $\mathbf{2}$ & 600 & 338.961 & 322.000 & 5.26 \\
\hline $\mathbf{3}$ & 840 & 103.977 & 114.000 & 8.79 \\
\hline
\end{tabular}

It can be seen in table 5 , that the probabilistic results obtained from the model are quite close to the actual experimental results.

\section{Conclusions}

In this study, a methodology for predicting residual life of cutting tool is introduced which is intended for optimize the cost of machining and maximise the availability time of machine tool. Turning of Ti-6Al-4V is performed on a CNC turning centre and experimental data are collected. Statistical model is constructed based on these tool life data. Once the reliability model is developed, it can estimate expected useful life of a worn out cutting tool. Experimental results show that the estimated residual life is in good agreement with the experimental one. It can be concluded that, this approach of predicting remaining tool life is helpful for mass production of parts, made up of same workpiece material and with same type of cutting tool.

\section{References}

1. G. N. Sakharov, V. Ilinykh, V. Yu. Konyukhov, Soviet engineering research, Improvement of fastening elements in an assembled cutting tool, 10(11), 102-103 (1990)

2. H. Wiklund, Quality and Reliability Engineering International, Bayesian and regression approaches to on-line prediction of residual tool life, 14(5), 303-309 (1998)

3. R. E. DeVor, D. L. Anderson, W. J. Zdeblick, Journal of Engineering for Industry Transactions of the ASME, Tool Life Variation and its Influence on the Development of Tool Life Models, 99, 578-584 (Sec B) (1977)

4. K. Hitomi, N. Nakamura, S. Inoue, Manufacturing Science and Engineering, Reliability analysis of cutting tools, 101(2), 185-190 (1979)

5. H. Negishi, K. Aoki, Precis Machining Investigations on reliability of carbide cutting tools, 42(6), 578-589 (1976)
6. C. E. P. Rodriguez, Souza de, Reliability Engineering \& System Safety, Reliability concepts applied to cutting tool change time, 95(8), 866-873 (2010)

7. X. ShengSi, W. Wang, C. HuaHu, D. HuaZhou, European Journal of Operational Research, Remaining useful life estimation $-A$ review on the statistical data driven approaches, 213, 1-14 (2011)

8. T. Benkedjouh, K. Medjaher, N. Zerhouni, and S. Rechak, Journal of Intelligent Manufacturing, Health assessment and life prediction of cutting tools based on support vector regression, 26(2), 1-11 (2013)

9. N. Gebraeel, M. Lawley, R. Liu, V. Prameswaran, IEEE Transactions on Industrial Electronics, Residual life predictions from vibration based degradation signals: a neural network approach, 51(3), 694-700 (2004)

10. M. Aramesh , M. H. Attia, H. A. Kishawy, M. Balazinski, CIRP Journal of Manufacturing Science and Technology, Estimating the remaining useful tool life of worn tools under different cutting parameters: A survival life analysis during turning of titanium metal matrix composites (Ti-MMCs), 12, 35-43 (2016)

11. H. A. Kishawy, S. Kannan, M. Balazinski, CIRP Annals - Manufacturing Technology, Analytical modeling of tool wear progression during turning particulate reinforced metal matrix composites, 54(1), 55-58, (2005)

12. Y. Shaban, M. Aramesh, S. Yacout, M. Balazinski, H. Attia, H. Kishawy, Journal on Engineering Manufacture, Optimal replacement times for machining tool during turning titanium metal matrix composites under variable machining conditions, 231(6), 924-932 (2017)

13. F. Ding, Z. He, International Journal of Advanced Manufacturing Technology, Cutting tool wear monitoring for reliability analysis using proportional hazards model, 57, 565-574 (2011)

14. R. J. Cook, J. F. Lawless, Springer, The statistical analysis of recurrent events, (2007)

15. D. Banjevic, A. Jardine, V. Makis, M. Ennis, INFOROTTAWA, A control-limit policy and software for condition based maintenance optimization, 39, 32-50 (2001)

16. https://www.sandvik.coromant.com/engb/products/tmax_p/Pages/default.aspx , (2018) 